Research Article

\title{
Comparison of 25- and 27-Gauge Pars Plana Vitrectomy in Repairing Primary Rhegmatogenous Retinal Detachment
}

\author{
Keiko Otsuka, ${ }_{1}^{1}$ Hisanori Imai ${ }^{1},{ }^{1}$ Ayaka Fujii, ${ }^{1}$ Akiko Miki, ${ }^{1}$ Mizuki Tagami, ${ }^{2}$ \\ Atsushi Azumi, ${ }^{2}$ and Makoto Nakamura ${ }^{1}{ }^{1}$ \\ ${ }^{1}$ Division of Ophthalmology, Department of Organ Therapeutics, Kobe University Graduate School of Medicine, \\ 7-5-2 Kusunoki-cho, Chuo-ku, Kobe 650-0017, Japan \\ ${ }^{2}$ Department of Ophthalmology, Kobe Kaisei Hospital, 3-11-15 Shinoharakitamati, Nada-ku, Kobe 657-0068, Japan
}

Correspondence should be addressed to Hisanori Imai; hisimai@med.kobe-u.ac.jp

Received 12 March 2018; Accepted 6 May 2018; Published 25 June 2018

Academic Editor: Ala Moshiri

Copyright (C) 2018 Keiko Otsuka et al. This is an open access article distributed under the Creative Commons Attribution License, which permits unrestricted use, distribution, and reproduction in any medium, provided the original work is properly cited.

Aim. To compare the anatomic and visual outcomes of 25-gauge (25G), and 27-gauge (27G) transconjunctival sutureless pars plana vitrectomy (TSV) for the management of primary rhegmatogeneous retinal detachment (RRD). Design. A retrospective nonrandomized clinical trial. Methods. A retrospective comparative analysis of 62 consecutive eyes from 62 patients with 6 months of follow-up was performed. Results. Thirty-two patients underwent 25G TSV, and 30 patients underwent 27G TSV for the treatment of primary RRD. There was no significant difference in baseline demographic and preoperative ocular characteristics between the two groups. The initial and final anatomical success rates were $93.8 \%$ and $100 \%$ in $25 \mathrm{G}$ TSV and $96.7 \%$ and $100 \%$ in 27G TSV, respectively ( $p=1$ and $p=1$, resp.). Preoperative best-corrected visual acuity (BCVA) $(\operatorname{logMAR})$ was $0.44 \pm 0.69$ and $0.38 \pm 0.61$ for $25 \mathrm{G}$ and $27 \mathrm{G}$ TSV, respectively $(p=0.73)$. The final follow-up BCVA was $0.07 \pm 0.25$ and -0.020 .17 for $25 \mathrm{G}$ and $27 \mathrm{G}$ TSV, respectively $(p=0.16)$. The final BCVA was significantly better than the preoperative BCVA in both groups ( $p=0.02$ and $p=0.002$, resp.). Preoperative intraocular pressure (IOP) ( $\mathrm{mmHg}$ ) was $13.0 \pm 3.5$ in $25 \mathrm{G}$ TSV and $14.3 \pm 2.8$ in $27 \mathrm{G}$ TSV ( $p=0.11$ ). IOP did not statistically significantly change in both groups during the follow-up period $(p=0.63$ and $p=0.21$, resp.). Conclusion. The $27 \mathrm{G}$ TSV system is safe and useful for RRD treatment as 25G TSV.

\section{Introduction}

Since the transconjunctival sutureless pars plana vitrectomy (TSV) with 25-gauge (25G) and 23-gauge instrumentation was introduced, there is an accumulating trend toward TSV as the first choice for the treatment of a variety of vitreoretinal surgical indications [1-3]. The advantages of TSV including the small incision, self-sealing, decreased surgical trauma, and less postoperative inflammation provide patients better postoperative comfort, less postoperative astigmatism, and earlier visual recovery compared to the traditional 20-gauge vitrectomy system [4-8]. In 2010, Oshima et al. first reported a preliminary study regarding the safety and practicality of the 27 -gauge $(27 \mathrm{G})$ instrument system for the vitreoretinal surgery [9]. Although the low rigidity of $27 \mathrm{G}$ instruments have been reported, several reports have suggested the clinical outcomes and short-term safety profile of 27G TSV for a variety of surgical indications, including rhegmatogeneous retinal detachment (RRD) [10-14]. However, there remained big concerns whether all surgeons can manage the $27 \mathrm{G}$ instrument especially on peripheral vitreoretinal disorders because the low instrument rigidity of $27 \mathrm{G}$ sometimes cause the difficulty of the operation and may impact the results especially for inexperienced surgeons.

In this study, we performed a retrospective comparative study to examine the anatomical success rates and complications of $25 \mathrm{G}$ and $27 \mathrm{G}$ TSV in the repair of primary RRD.

\section{Patients and Methods}

We performed retrospective analyses of the medical records of 62 consecutive eyes of 62 patients with primary 
uncomplicated RRD treated with $25 \mathrm{G}$ (group A) or $27 \mathrm{G}$ (group B) TSV. This study is a nonrandomized, retrospective comparative clinical trial. Our study was performed after obtaining the approval of the institutional review board in Kobe University School of Medicine and Kobe Kaisei Hospital. The procedure used conformed to the Tenets of the Declaration of Helsinki. Patients were enrolled from January 2014 through June 2015. Surgeries were performed by six surgeons. Ophthalmic residents in each hospital assisted all surgeries. Three surgeons who had experienced over 1000 vitreoretinal surgeries are thought to be experienced doctors, and the other three surgeons who had experienced less than 100 vitreoretinal surgeries are thought to be inexperienced doctors. Eyes with giant retinal tears, proliferative vitreoretinopathy, atopic dermatitis, and a history of prior surgery for RRD were excluded. The patients were followed up at least for 6 months after the surgery. The following variables were analyzed: sex, age, primary surgeon, preoperative bestcorrected visual acuity (BCVA), postoperative BCVA, preoperative intraocular pressure (IOP), postoperative IOP, the primary anatomical success rate, the final anatomical success rate, the number of retinal breaks, locations of retinal breaks, the number of quadrants involved, the presence or absence of the macular detachment, the number of eyes who needed the suture for sclerotomy sites, the operative time, and the lens status.

2.1. Statistical Methods. The chi-square test and Fisher's exact probability test for dichotomous variables and unpaired $t$-test for continuous variables were used to compare parameters listed above between the two groups. Paired $t$-test was used for comparison between pre- and postoperative VA within the same group. We used the Kruskal-Wallis $H$-test to examine the transition of IOP in each group.

For logistic multiple regression analysis, univariate analysis was performed to establish the relationships between explanatory variables and the primary anatomic success rate, using the chi-square test, Fisher's exact probability test, and unpaired $t$-test. The level of statistical significance was set at $p<0.20$. The variables found to be significant in univariate analysis were analyzed with backward logistic multiple regression analysis, using the MedCalc (MedCalc version 12.7.5.0; MedCalc Software, Mariakerke, Belgium). Statistical significance was inferred for $p<0.05$. The Landolt decimal VA was converted to logarithmic minimum angle of resolution (logMAR) for statistical analysis.

2.2. Surgical Procedures. All surgeries were performed under sub-Tenon anesthesia consisting of approximately $4 \mathrm{~mL}$ of 2\% lidocaine. The Constellation Vision system (Alcon Laboratories, Inc., Forth Worth, TX, USA) was used for both $25 \mathrm{G}$ and $27 \mathrm{G}$ TSV with a wide-angle noncontact viewing system (Resight ${ }^{\circledR}$; Carl Zeiss Meditec AG, Jena, Germany). Three cannulas were created with conjunctival displacement and oblique-angled sclerotomies in the inferotemporal, superotemporal, and superonasal quadrants $3.0-4.0 \mathrm{~mm}$ posterior to the limbus. $27 \mathrm{G}$ twin chandelier illumination fibers (Eckardt TwinLight Chandelier, Dorc International, Zuidland, Netherlands) or 29G twin chandelier illumination fibers (Oshima dual, Synergetics USA, Inc.) were placed at $4.0 \mathrm{~mm}$ behind the limbus for wide-angle intraocular illumination. Before vitrectomy, for better visualization and shaving of peripheral vitreous, cataract extraction with phacoemulsification using the same machine and intraocular lens implantation were performed for all phakic eyes. Following the core vitrectomy, triamcinolone acetonide (MaQaid, Wakamoto Pharmaceutical, Tokyo, Japan) was injected to visualize vitreous gel during midperipheral vitrectomy. Then, the peripheral vitreous gel was shaved for $360^{\circ}$ with scleral indentation under a wide-angle noncontact viewing system. No internal drainage retinotomies was made in the majority of cases to avoid the awareness of a scotoma but made in the most dependent or anterior part of the detached retina if necessary. Subretinal fluid was evacuated from original tears or drainage retinotomy sites and followed by a complete fluid-air exchange. All retinal detachments were reattached intraoperatively. Endolaser photocoagulation was applied to completely surround all retinal breaks and drainage retinotomy sites. At the end of surgery, all eyes were flushed with $50 \mathrm{~mL}$ of mix of $20 \%$ SF6 gas to assure a complete exchange. Additional gas mixture was injected through the pars plana to adjust IOP if necessary. Any sclerotomy sites that were found to be leaking at the end of the surgery were sutured with 8-0 vicryl suture. Normal IOP was checked by tactile examination. Subconjunctival corticosteroids were injected, and antibiotic ointment was administered at the end of the surgical procedure. All patients were kept in a prone position for 1 to 2 weeks after surgery, at least until less than $50 \%$ gas fill.

\section{Results}

Table 1 summarizes patients' perioperative demographic data. Thirty-two eyes underwent 25G TSV (group A) and 30 eyes with $27 \mathrm{G}$ TSV (group B). There were 24 men in group $\mathrm{A}$, and 18 men in group $\mathrm{B}(p=0.32)$. The mean $\pm \mathrm{SD}$ age was $59 \pm 13$ years in group A and $55 \pm 9$ years in group B $(p=0.15)$. Their preoperative BCVA (log MAR) was $0.44 \pm$ 0.69 units in group A and $0.38 \pm 0.61$ in group $\mathrm{B}(p=0.73)$. Their postoperative BCVA at the last visit was $0.07 \pm 0.25$ in group A and $-0.02 \pm 0.17$ in group B $(p=0.16)$. The final BCVA was significantly better than the preoperative BCVA in both groups ( $p=0.02, p=0.002$, resp.). The initial and final anatomical success rates were $93.8 \%$ and $100 \%$ in group $A$ and $96.7 \%$ and $100 \%$ in group B, respectively ( $p=1$ and $p=1$, resp.). The mean \pm SD number of retinal beaks was $1.6 \pm 1.2$ in group A and $1.9 \pm 1.2$ in group B $(p=0.30)$. Twenty-three eyes had original breaks at the superior quadrant, 8 eyes at the inferior quadrant, and 1 eye at both the quadrants in group A. On the contrary, nineteen eyes had original breaks at the superior quadrant, 9 eyes at the inferior quadrant, and 2 eyes at both the quadrants in group $B$. There were no statistical differences in the location and the number of the breaks between both groups $(p=0.96)$. Twenty-seven eyes had RRD involving one or two quadrants, and five eyes had more extensive RRD involving three or 
TABle 1: Perioperative demographic data of the patients.

\begin{tabular}{|c|c|c|c|}
\hline Characteristics & 25 gauge & 27 gauge & $p$ value \\
\hline Number of eyes & 32 & 30 & - \\
\hline Sex, male/female & $24 / 8$ & $18 / 12$ & 0.32 \\
\hline Age (years), mean $\pm S D$ & $59 \pm 13$ & $55 \pm 9$ & 0.15 \\
\hline Preoperative visual acuity (logMAR), mean \pm SD & $0.44 \pm 0.69$ & $0.38 \pm 0.61$ & 0.73 \\
\hline Visual acuity at the last visit (logMAR), mean \pm SD & $0.07 \pm 0.25$ & $-0.02 \pm 0.17$ & 0.16 \\
\hline Preoperative intraocular pressure $(\mathrm{mmHg})$, mean \pm SD & $13.0 \pm 3.5$ & $14.3 \pm 2.8$ & 0.11 \\
\hline Initial anatomical success & $30(93.8 \%)$ & $29(96.7 \%)$ & 1 \\
\hline Final anatomical success & $32(100 \%)$ & $30(100 \%)$ & 1 \\
\hline Number of breaks, mean \pm SD & $1.6 \pm 1.2$ & $1.9 \pm 1.2$ & 0.30 \\
\hline $\begin{array}{l}\text { Location of breaks, } \\
\text { superior/inferior/both/undetectable }\end{array}$ & $23 / 8 / 1 / 0$ & $19 / 9 / 2 / 0$ & 0.96 \\
\hline Quadrant of retinal detachment, 1/2/3/4 & $10 / 17 / 4 / 1$ & $10 / 17 / 3 / 0$ & 0.99 \\
\hline Macular detachment, macular on/macular off & $23 / 9$ & $15 / 15$ & 0.13 \\
\hline The number of sclerotomies that required sutures & 9 & 4 & 0.30 \\
\hline Operative time $(\mathrm{min})$, mean $\pm \mathrm{SD}$ & $103.3 \pm 39.9$ & $98.4 \pm 28.3$ & 0.77 \\
\hline Lens status, phakic/pseudophakic/aphakic & $24 / 7 / 1$ & $27 / 3 / 0$ & 0.61 \\
\hline
\end{tabular}

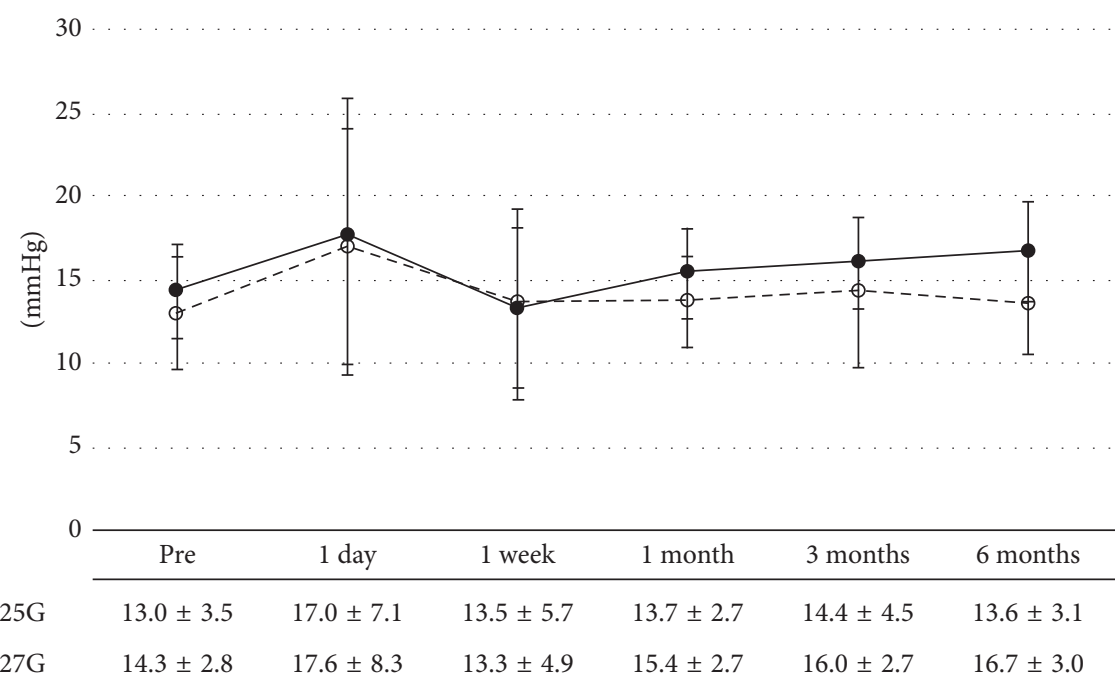

Figure 1: Time course changes in intraocular pressure (IOP). The mean IOP at baseline was $13.0 \pm 3.5 \mathrm{mmHg}$ in group A and $14.3 \pm$ $2.8 \mathrm{mmHg}$ in group B. At 1 day, 1 week, 1 month, 3 months, and 6 months postoperatively, the IOP was 17.0 $\pm 7.1,13.5 \pm 5.7,13.7 \pm 2.7$, $14.4 \pm 4.5$, and $13.6 \pm 3.1 \mathrm{mmHg}$, respectively, in group A, and $17.6 \pm 8.3,13.3 \pm 4.9,15.4 \pm 2.7,16.0 \pm 2.7$, and $16.7 \pm 3.0 \mathrm{mmHg}, \mathrm{re}-$ spectively, in group B. IOP did not statistically significantly change in both groups during the follow-up period $(p=0.63$ and $p=0.21$, resp.).

four quadrants in group A. Twenty-seven eyes had RRD involving one or two quadrants, and three eyes had more extensive RRD involving three or four quadrants in group B. There was no statistical difference in the location and extent of RRD between both groups $(p=0.99)$. The macula was attached preoperatively in $23(71.9 \%)$ eyes in group A and 15 $(50 \%)$ in group B $(p=0.13)$. The number of wounds that required sutures was $9 / 96$ in group $A$ and $4 / 90$ in group $B$ $(p=0.30)$. The operative time (minutes) was $103.3 \pm 39.9$ in group A and $98.4 \pm 28.3$ in group B $(p=0.77)$.

We evaluated time course changes in IOP during the follow-up period. Preoperative IOP $(\mathrm{mmHg})$ was $13.0 \pm 3.5$ in group A and $14.3 \pm 2.8$ in group B $(p=0.11)$. IOP did not statistically significantly change in both groups during the follow-up period ( $p=0.63$ and $p=0.21$, resp.) (Figure 1). No eye developed postoperative hypotony in both groups.

We experienced retinal redetachment in both groups (Table 2). The rate of these complications was similar between the two groups. We performed additional 27G TSV with $20 \%$ sulfur hexafluoride gas tamponade for the treatment of retinal redetachment by experienced doctors, and all eyes obtained the final retinal attachment.

As a result of univariate analysis, the following variables were selected to perform backward logistic multiple regression analysis: age, number of quadrants involved, and lens status. The logistic multiple regression analysis revealed that all variables were not associated with the primary anatomic success (Table 3). 
TABLE 2: Details of patients with postoperative complications.

\begin{tabular}{lccc}
\hline Complication & 25 gauge & 27 gauge & Second treatment \\
\hline Retinal redetachment & 2 & 1 & $\begin{array}{c}27 \mathrm{GPPV}+\mathrm{SF} 6 \\
\text { tamponade }\end{array}$ \\
\hline
\end{tabular}

$27 \mathrm{GPPV}=27$-gauge pars plana vitrectomy; SF6 = sulfur hexafluoride.

TABle 3: Analysis for the establishment of the relationships between explanatory variables and the primary anatomic success.

\begin{tabular}{|c|c|c|c|}
\hline \multirow{2}{*}{ Explanatory variables } & \multirow{2}{*}{$\begin{array}{c}\text { Univariate } \\
\text { analysis } \\
p \text { value }\end{array}$} & \multicolumn{2}{|c|}{$\begin{array}{c}\text { Logistic regression } \\
\text { analysis }\end{array}$} \\
\hline & & $\begin{array}{c}p \\
\text { value }\end{array}$ & OR $(95 \% \mathrm{CI})$ \\
\hline Sex & 0.26 & $\mathrm{NE}$ & \\
\hline Age & 0.04 & 0.054 & $\begin{array}{c}0.88 \\
(0.78-1.00)\end{array}$ \\
\hline Preoperative visual acuity & 0.31 & $\mathrm{NE}$ & \\
\hline Visual acuity at the last visit & 0.42 & $\mathrm{NE}$ & \\
\hline Primary surgeon & 0.24 & $\mathrm{NE}$ & \\
\hline Number of breaks & 0.91 & $\mathrm{NE}$ & \\
\hline Location of breaks & 0.44 & $\mathrm{NE}$ & \\
\hline $\begin{array}{l}\text { Quadrant of retinal } \\
\text { detachment }\end{array}$ & 0.19 & Not in & $\begin{array}{l}\text { cluded in the } \\
\text { model }\end{array}$ \\
\hline Macular detachment & 0.28 & $\mathrm{NE}$ & \\
\hline Operative time & 0.54 & $\mathrm{NE}$ & \\
\hline Lens status & 0.08 & Not in & $\begin{array}{l}\text { cluded in the } \\
\text { model }\end{array}$ \\
\hline Gauge of vitreous cutter & 1 & $\mathrm{NE}$ & \\
\hline
\end{tabular}

$\mathrm{OR}=$ odds ratio; $\mathrm{CI}=$ confidence interval $\mathrm{NE}=$ not entered into multiple regression analysis.

\section{Discussion}

As previously reported $[9,15]$, in $27 \mathrm{G}$ TSV, the vitreous cutter used is short in length and low in stiffness, which bears clinicians, especially for surgically inexperienced doctors, concern regarding the possibility of compromised safety and operability in applying the $27 \mathrm{G}$ TSV system on the peripheral vitreoretinal diseases compared with the established larger-gauge TSV systems. In this study, we reported that the 27G TSV system provided anatomical results comparable to those obtained in 25G TSV. This result is compatible with the previous reports $[13,14]$. In addition, the result of logistic regression analysis did not indicate any association between the primary anatomic success rate and explanatory variables, including the primary surgeon and gauge of vitreous cutter. These results indicate that $27 \mathrm{G}$ TSV have a potential for the practical use in the treatment of RRD for all surgeons, including inexperienced doctors.

Other concerns related to $27 \mathrm{G}$ TSV has been the low aspiration efficiency [15], which may extend the operation time. Mitsui et al. reported that, in 27G TSV, the operation time was significantly longer than that in $25 \mathrm{G}$ TSV for the epiretinal membrane [12]. On the contrary, previous reports suggested that the duration of vitreous removal is not different between $25 \mathrm{G}$ and $27 \mathrm{G}$ TSV for RRD $[13,14]$. Our results also did not show a significant difference in operation time between $25 \mathrm{G}$ and $27 \mathrm{G}$ TSV for RRD. In terms of the core vitreoctomy process, the surgeon indeed felt that the aspiration efficiency of $27 \mathrm{G}$ TSV was obviously inferior to that of $25 \mathrm{G}$ TSV, as theoretically anticipated [15]. However, during the vitreous gel shaving in the vicinity of a detached retina, the critical procedure of the peripheral vitrectomy for RRD, 27G TSV was rather safe because of less frequent flapping of the retina due to lower aspiration efficiency compared with the 25G TSV. As a result, the total operation time did not differ between the two systems. Moreover, in the epiretinal membrane surgery reported by Mitsui et al. [12], peripheral vitrectomy was not as strenuous as that in RRD surgery. This difference in the required procedures could also account for the discrepant results obtained between the studies. Collectively, we believe that our results indicate the equivalency between $25 \mathrm{G}$ and $27 \mathrm{G}$ TSV for the RRD treatment. Accumulating cases are needed to confirm our preliminary observations.

Generally, 27G TSV requires a smaller incision, which suggests the possibility of excellent self-closing of the wound, compared to other vitrectomies with larger gauges $[9,15]$. We monitored IOP for 6 months after surgery and found no significant difference during the follow-up period. We also found no significant difference in the number of wounds that required sutures between the two systems. In the 27G TSV performed by Mitsui et al. [12], as the stiffness of the cutter was low, the cutter had to be manipulated more dynamically; thus, wound closing might not have been as good as expected. For RRD, the cutter had to be manipulated more dynamically for the peripheral vitrectomy. This may be the reason why no difference was found between the two gauges with regard to the number of wounds that required sutures. In addition, as this research focused on the RRD, the surgery was completed by filling the vitreous cavity with SF6 gas in all the cases. Previous reports have indicated that when a gas tamponade was performed, the postoperative IOP was more stable than when it was not used $[9,16]$. Therefore, the use of a gas tamponade may be a reason why the two gauges did not differ in IOP.

This study has potential limitations. First, it is a retrospective study, and there may have been a bias of patient selection. Another problem is that the sample size was relatively small. The results of large-scale, prospective research studies in the future are needed.

In conclusions, we performed a comparative study of outcomes between 25G and 27G TSV for RRD. The surgical results of the two gauges were equivalent with the similar effectiveness. We believe that $27 \mathrm{G} \mathrm{TSV}$ is as useful as $25 \mathrm{G}$ for $\mathrm{RRD}$, which is a disease of the peripheral retina.

\section{Data Availability}

The data used to support the findings of this study are restricted by the institutional review board in Kobe University School of Medicine and Kobe Kaisei Hospital in order to protect patient privacy. Data are available from Hisanori Imai, who is the corresponding author of this manuscript, for researchers who meet the criteria for access to confidential data.

\section{Conflicts of Interest}

The authors declare that there are no conflicts of interest regarding the publication of this paper. 


\section{References}

[1] C. I. Falkner-Radler, J. S. Myung, S Moussa et al., "Trends in primary retinal detachment surgery: results of a bicenter study," Retina, vol. 31, no. 5, pp. 928-936, 2011.

[2] J. D. Ho, S. W. Liou, C. Y. Tsai, R. J. Tsai, and H. C. Lin, "Trends and outcomes of treatment for primary rhegmatogenous retinal detachment: a 9-year nationwide populationbased study," Eye, vol. 23, no. 3, pp. 669-675, 2009.

[3] C. W. Wong, W. L. Wong, I. Y. Yeo et al., "Trends and factors related to outcomes for primary rhegmatogenous retinal detachment surgery in a large Asian tertiary eye center," Retina, vol. 34, no. 4, pp. 684-692, 2014.

[4] Y. H. Yoon, D. S. Kim, J. G. Kim, and J. U. Hwang, "Sutureless vitreoretinal surgery using a new 25 -gauge transconjunctival system," Ophthalmic Surgery, Lasers \& Imaging, vol. 37, no. 1, pp. 12-19, 2006.

[5] S. Rizzo, F. Genovesi-Ebert, S. Murri et al., "25-gauge, sutureless vitrectomy and standard 20-gauge pars plana vitrectomy in idiopathic epiretinal membrane surgery: a comparative pilot study," Graefe's Archive for Clinical and Experimental Ophthalmology, vol. 244, no. 4, pp. 472-479, 2006.

[6] K. Kadonosono, T. Yamakawa, E. Uchio, Y. Yanagi, Y. Tamaki, and M. Araie, "Comparison of visual function after epiretinal membrane removal by 20 -gauge and 25 -gauge vitrectomy," American Journal of Ophthalmology, vol. 142, no. 3, pp. 513-515, 2006.

[7] D. H. Park, J. P. Shin, and S. Y. Kim, "Surgically induced astigmatism in combined phacoemulsification and vitrectomy: 23-gauge transconjunctival sutureless vitrectomy versus 20-gauge standard vitrectomy," Graefe's Archive for Clinical and Experimental Ophthalmology, vol. 247, no. 10, pp. 13311337, 2009.

[8] G. Galway, B. Drury, B. G. Cronin, and R. D. Bourke, “A comparison of induced astigmatism in 20- vs 25-gauge vitrectomy procedures," Eye, vol. 24, no. 2, pp. 315-317, 2010.

[9] Y. Oshima, T. Wakabayashi, T. Sato, M. Ohji, and Y. A. Tano, "27-gauge instrument system for transconjunctival sutureless microincision vitrectomy surgery," Ophthalmology, vol. 117, no. 1, pp. 93.e2-102.e2, 2010.

[10] M. A. Khan, A. Shahlaee, B. Toussaint et al., "Outcomes of 27 gauge microincision vitrectomy surgery for posterior segment disease," American Journal of Ophthalmology, vol. 161, pp. 36. e2-43.e2, 2016.

[11] S. Rizzo, F. Barca, T. Caporossi, and C. Mariotti, "Twentyseven-gauge vitrectomy for various vitreoretinal diseases," Retina, vol. 35, no. 6, pp. 1273-1278, 2015.

[12] K. Mitsui, J. Kogo, H. Takeda et al., "Comparative study of 27gauge vs 25 -gauge vitrectomy for epiretinal membrane," Eye, vol. 30 , no. 4 , pp. 538-544, 2016.

[13] S. Rizzo, S. Polizzi, F. Barca, T. Caporossi, and G. Virgili, "Comparative study of 27-gauge versus 25 -gauge vitrectomy for the treatment of primary rhegmatogenous retinal detachment," Journal of Ophthalmology, vol. 2017, Article ID 6384985, 5 pages, 2017.

[14] M. R. Romano, G. Cennamo, M. Ferrara, M. Cennamo, and G. Cennamo, "Twenty-seven-gauge versus 25-gauge vitrectomy for primary rhegmatogenous retinal detachment," Retina, vol. 37, no. 4, pp. 637-642, 2017.

[15] S. Osawa and Y. Oshima, "27-Gauge vitrectomy," in Developments in Ophthalmology, pp. 54-62, Karger Publishers, Basel, Switzerland, 2014.
[16] S. Yamane, K. Kadonosono, M. Inoue, S. Kobayashi, Y. Watanabe, and A. Arakawa, "Effect of intravitreal gas tamponade for sutureless vitrectomy wounds: three-dimensional corneal and anterior segment optical coherence tomography study," Retina, vol. 31, no. 4, pp. 702-706, 2011. 


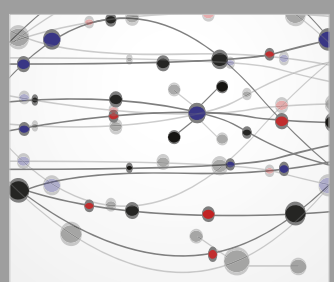

The Scientific World Journal
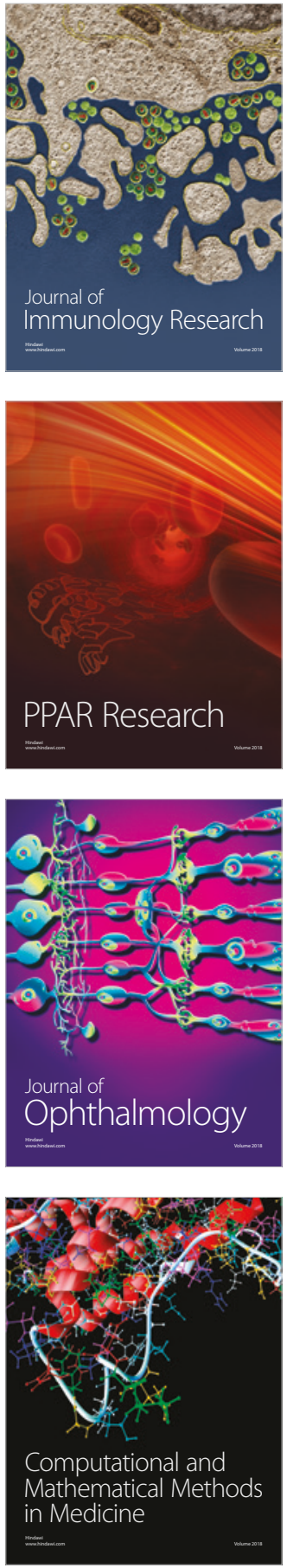

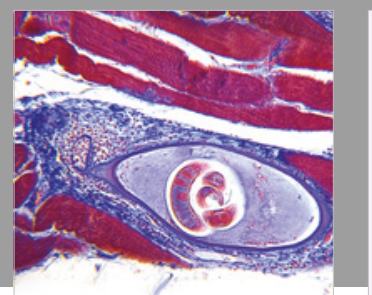

Gastroenterology Research and Practice

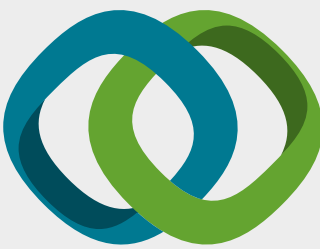

\section{Hindawi}

Submit your manuscripts at

www.hindawi.com
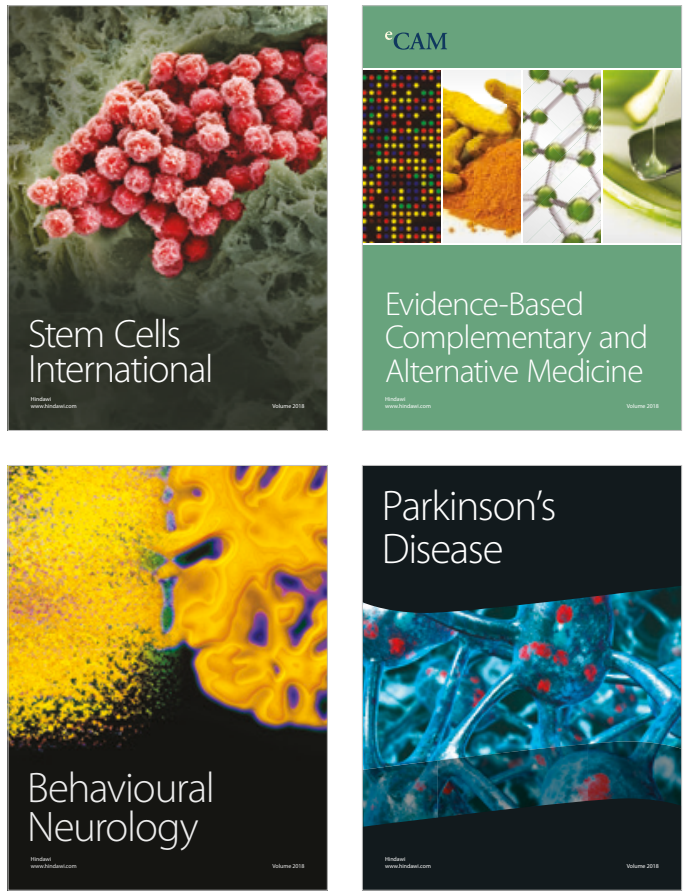

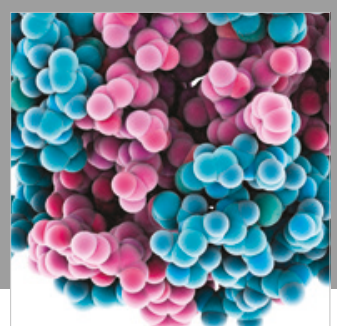

ournal of

Diabetes Research

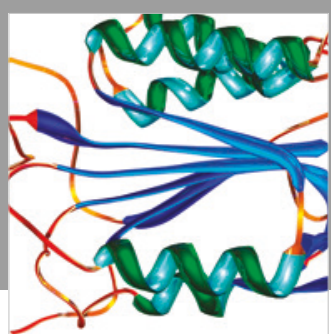

Disease Markers
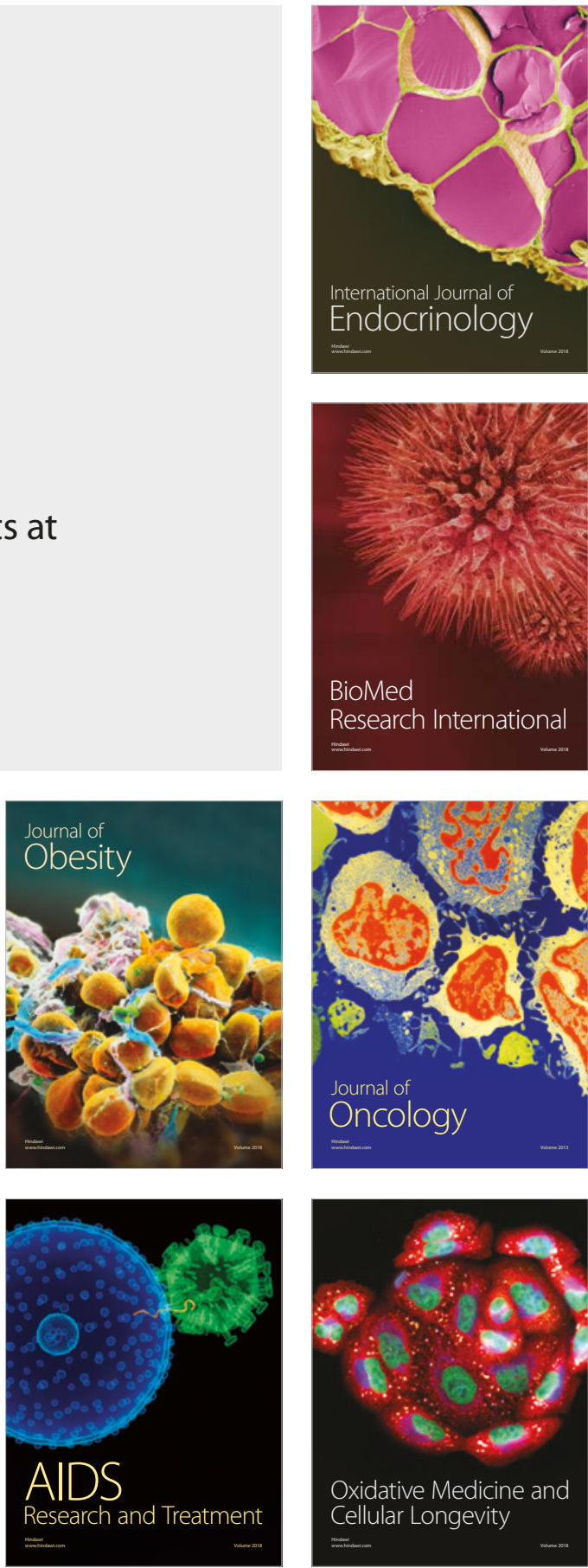